\title{
An uncommon complication of central venous catheter placement
}

\section{Ray Matthews, Travealyan Walker, Kenneth L Wilson, Omar K Danner}

\begin{abstract}
Introduction: The most commonly used inferior vena cava filters in the United States are the Greenfield filters. Case Report: We report a case of a 60-year-old man with ensnarement of a Greenfield filter by a J-tip guide wire used to insert a central venous catheter from the femoral approach. Conclusion: We conclude that ensnarement of the filter by the guide wire is a preventable complication.
\end{abstract}

Keywords: Greenfield filter, Ensnarement, Central venous

$* * * * * * * * *$

Matthews LR, Walker T, Wilson KL, Danner OK. An uncommon complication of central venous catheter placement. International Journal of Case Reports and Images 2013;4(5):287-289.

$* * * * * * * * *$

doi:10.5348/ijcri-2013-05-314-CR-11

L Ray Matthews ${ }^{1}$, Travealyan Walker ${ }^{1}$, Kenneth L Wilson ${ }^{1}$, Omar K Danner ${ }^{1}$

Affiliations: ${ }^{1}$ Morehouse School of Medicine, Department of Surgery, 720 Westview Drive, Atlanta.

Corresponding Author: L Ray Matthews, MD, Orehouse School of Medicine, Department of Surgery, 720 Westview Drive, Atlanta, GA 30310; Contact No: (404) 616-1415; Fax No: (404) 616-1417; Email: lematthews@msm.edu

Received: 03 March 2011

Accepted: 26 April 2011

Published: 01 May 2013

\section{INTRODUCTION}

Greenfield filters are commonly used for the treatment of deep vein thrombosis (DVT) and pulmonary embolism (PE) in patients with contraindications to anticoagulation. We report a case of ensnarement of a Greenfield filter by a J-tip guide wire used to insert a central venous catheter from the femoral approach.

\section{CASE REPORT}

A 6o-year-old man with a history of diabetes mellitus, hypertension, morbid obesity and ventilatorassociated pneumonia was admitted to a surgical intensive care unit for a subarachnoid hemorrhage after an assault. During placement of a right femoral catheter, the J-tip guide wire was advanced for approximately $55 \mathrm{~cm}$. Subsequently, the $J$-tip guide wire could not be removed even with excessive force. When the patient presented to the physical examination was unremarkable except for a foreign body (guide wire) protruding from the patient's right groin area. A radiograph showed the Greenfield filter in the proper position with the J-tip guide wire ensnared in the Greenfield filter (Figure 1). The J-tip guide wire was removed using fluoroscopic visualization with a filter sheath without any complications (Figure 2). An inferior vena cavogram showed no extravasation. The patient was discharged home two weeks later without any complications.

\section{DISCUSSION}

The most commonly used filter in the United States is the Greenfield filter. These filters work by allowing venous flow through the filter while capturing the emboli. Ensnarement of the filter by the guide wire is a preventable complication that can happen from the jugular, subclavian and femoral approaches $[1,2]$.

Ensnarement of the inferior vena cava (IVC) filter is noted clinically as the wire becoming "stuck" during 


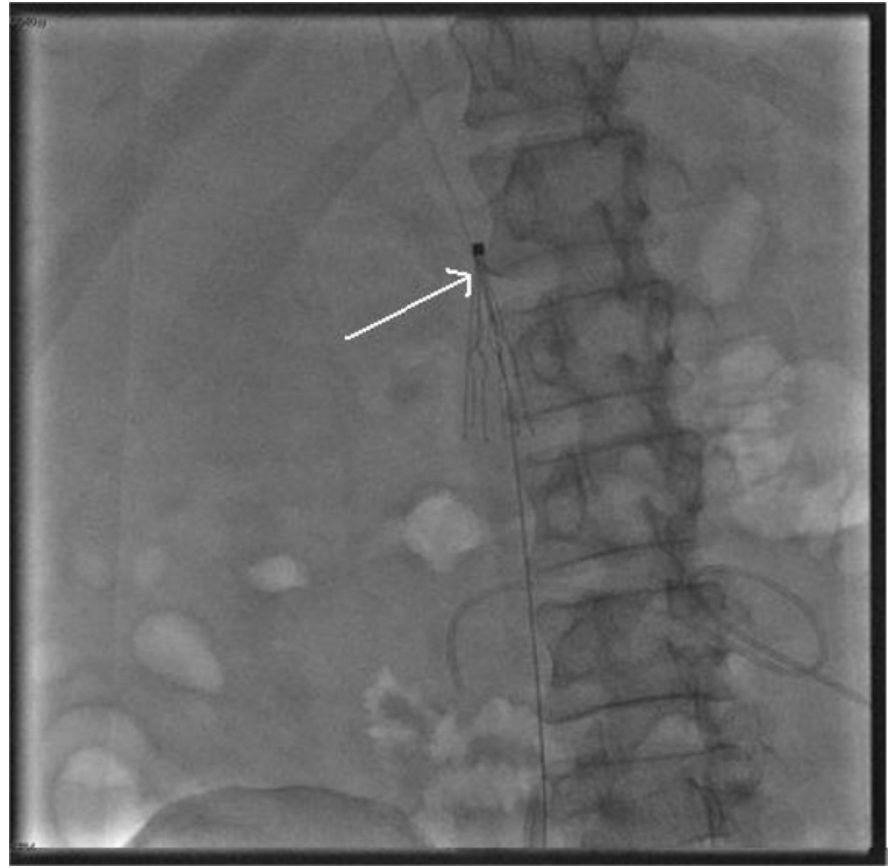

Figure 1: A plain abdominal radiograph showing the J-tip guide wire ensnared in the Greenfield filter.

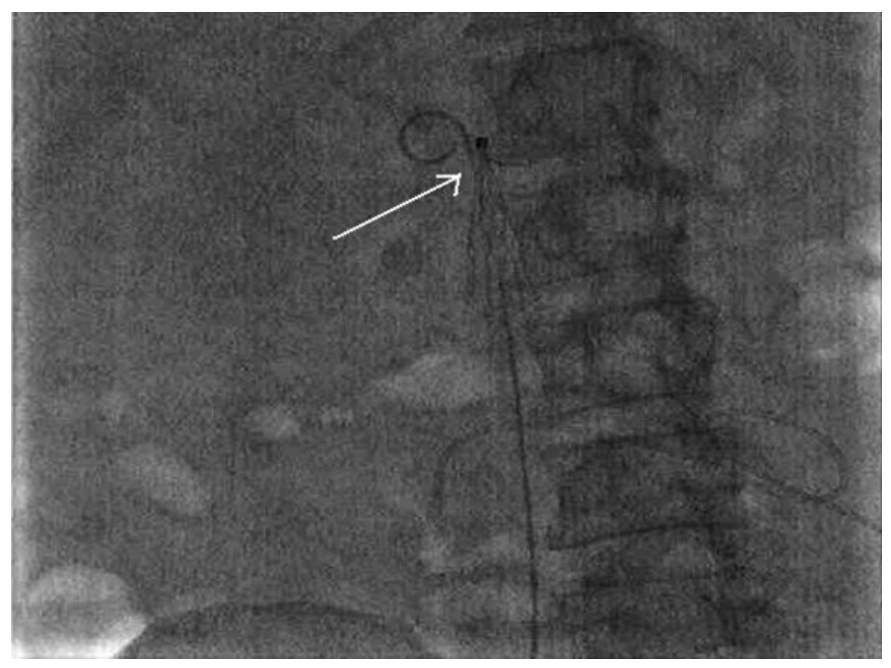

Figure 2: Fluoroscopic visualization using a filter sheath to remove the J-tip guide wire.

wire withdrawal [3]. Further attempts to remove the wire should be halted immediately. Any attempt to remove the guide wire with force can cause catastrophic complications including filter caval disruption, perforation, arrhythmias, cardiac tamponade and even death $[3,4]$.

To prevent this complication, all patients should be queried about the presence of an IVC filter before elective insertion of a central venous catheter. In the event that a history cannot be obtained from the patient, an abdominal radiograph will show the presence of this device. If a Greenfield filter is present, to avoid this type of complication, the straight end of the J-tip guide wire should be used to place the central venous catheter in patients with Greenfield filters.
Treatment of this complication demands emergent consultation with interventional radiology. Techniques used to free the guide wire include using fluoroscopic visualization and placement of a vascular sheath and snares to work the guide wire free.

\section{CONCLUSION}

We present a case of ensnarement of Greenfiled filter by $\mathrm{J}$-tip guide wire which is a preventable complication of central venous catheter placement. It can be avoided by taking a detailed patient history and/or abdominal radiographs when placing central venous catheters.

$$
* * * * * * * * *
$$

\section{Author Contributions}

L Ray Matthews - Substantial contributions to conception and design, Acquisition of data, Analysis and interpretation of data, Drafting the article, Revising it critically for important intellectual content, Final approval of the version to be published

Travealyan Walker - Analysis and interpretation of data, Drafting the article, Revising it critically for important intellectual content, Final approval of the version to be published

Kenneth L Wilson - Analysis and interpretation of data, Drafting the article, Revising it critically for important intellectual content, Final approval of the version to be published

Omar K Danner - Analysis and interpretation of data, Drafting the article, Revising it critically for important intellectual content, Final approval of the version to be published

\section{Guarantor}

The corresponding author is the guarantor of submission.

\section{Conflict of Interest}

Authors declare no conflict of interest.

\section{Copyright}

(C) L Ray Matthews et al. 2013; This article is distributed under the terms of Creative Commons attribution 3.0 License which permits unrestricted use, distribution and reproduction in any means provided the original authors and original publisher are properly credited. (Please see www.ijcasereportsandimages.com/copyright-policy.php for more information.)

\section{REFERENCES}

1. Dardik A, Campbell KA, Yeo CJ, Lipsett PA. Vena cava filter ensnarement and delayed migration: an unusual series of cases. J Vasc Surg 1997;26(5):869-74. 
2. Munir MA, Chien SQ. An in situ technique to retrieve an entrapped J-tip guidewire from an inferior vena cava filter. Anesth Analg 2002;95(2):308-9.

3. Stavropoulus SW, Itkin M, Trerotola SO. In vitro study of guide wire entrapment in currently available inferior vena cava filters. J Vasc Interv Radiol 2003;14(7):905-10.

4. Ermakov S, Hoyt JW. Pulmonary artery catheterization. Crit Care Clin 1992;8(4):773-806.
Access full text article on other devices

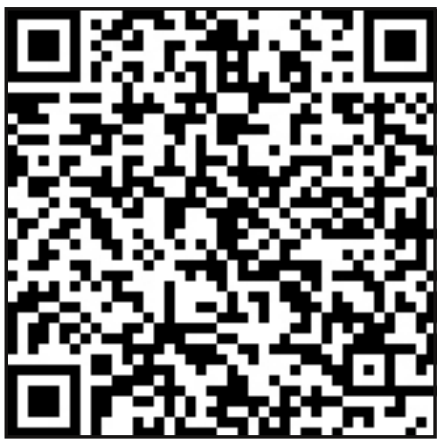

Access PDF of article on other devices

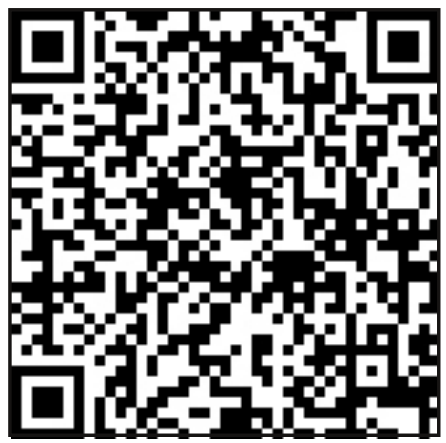

